\title{
Opinions of Egyptian Secondary School Teachers on Effectiveness of Hendy's 4Cs Model in Engaging Learning-Disabled Students
}

\author{
Mohamed H. Hendy \\ Beni-Suef University, Egypt
}

\begin{abstract}
Learning disabilities represent one of the most important issues that affect learning situations. They are very big challenge for teachers unless they become aware of physical, intellectual, emotional, behavioral, reading, hearing, and visual disabilities and use the suitable learning and teaching models and strategies that meet them. Since teachers' opinions towards using new learning models and strategies with those of learning disabilities are important, this study tried to identify if using Hendy's 4Cs model is effective to engage learning-disabled students according to opinions of secondary school teachers in Egypt. So, two research questions related to behavioral and cognitive engagement were presented and interpreted through this study. The results refereed that teachers who work in secondary schools of big numbers of students with learning disabilities perceived using Hendy's 4Cs model as effective to engage learning-disabled students behaviorally and cognitively. So the model can contribute in solving many problems related to disabled students according to the multiple roles of both teacher and students through the model phases.
\end{abstract}

\section{Introduction}

Learning disabilities are characterized by significant differences in the child's achievement in certain area as compared to overall intelligence. Students may exhibit a wide range of specific traits including deficits in reading comprehension or spoken language, writing, or reasoning ability. Inattention and perceptual difficulties may also be associated with learning disabilities. Other possible traits include, for example, unpredictable test performance, motor disorders, and challenging behaviors [19]. To deal with these problems, teachers should be aware of implications of learning theories that recommend engagement of students; specifically, those of learning disabilities. Learning models that are based on more than one theory are better through learning process. Hendy's 4Cs model is based on four learning theories; contextualism, connectivism, constructivism, and cognitivism. So, the model took its phases' names; which are contextualizing, connecting, constructing, cognitivizing. It is like a physical mental journey that takes learner from the exploration of ideas to the meaningful learning and long-term memory. There are flexible roles for both of teacher and learners to be practiced through each phase (see Figure 1). Performing these roles effectively can lead directly to the development of learner engagement, exploration of main ideas, learning connection, construction of knowledge, and deep learning; and then attaining meaningful learning and placing information in long-term memory [10].

\section{Theoretical Background:}

\section{- Hendy's 4Cs Model:}

Although working on neuroscience and educational psychology have provided us with varied learning theories, thinking should continue to explore new applicable models based on those theories to promote and maximize the efficiency and capacity of learning. The current model can be practiced according to four phases as follows [10]:

- Contextualizing: Contextual learning is based on the recognition that development of experiences requires learners to develop procedural knowledge during learning situations. Instruction aims directly at knowledge and skills learners need to perform tasks they have explored as important to them in their everyday lives [17]. So, through this phase of $4 \mathrm{Cs}$ model, learning situations depend on putting learners in instructional environments full of real-life materials and events, or in virtual learning environments that have the same components. As well as, investing the social events related to those components because effective contextual learning focuses on the social nature of real-world activities.

Practically, a study conducted by Kurniati and Others [15] found that using a contextual learning model helped to develop the level of learning and problem-solving abilities to high school students in Indonesia. Hutchinson [13] 
found that integrated contextual unites on science, mathematics, and technology helped develop motivation, self-direction, and retention of primary school students. Although the contextual learning through this phase can establish varied real life-contexts and stimulate thinking on real materials and events, there are some limitations for using only contextual learning in one situation. For instance, contextual learning tasks mostly address the visual learning style while learners have multiple learning styles such as verbal, auditory, creative and so on; which need to be considered during learning. Also, there is a difficulty of identifying the actual learning level that can be acquired completely through the contextual situation. Hereby, learners need to connect their learning to other situations and events verbally, virtually, and technologically.

- Connecting: Once learning tasks are being acquainted by students through the previous phase, learners can be guided to connect what they have actually observed to other contexts technologically. Within a connectivist-learning environment, knowledge is considered to flow through a network which contains "nodes" that can be an individual or group resource [3]. Therefore, learners use technology to create networks from which they can choose, personalize and make it as self-responsibility. Generally, through this phase of the 4Cs model, learners are guided to connect or link what they have observed to other situations through WWW, Emails, Wikis, Online Discussions, Social Networks, You Tube and any other technological tools which enable them to learn and share information with others. Hereby, the teacher is responsible about proposing more materials and events for learners to connect and link technologically with what in the real context. Siemens [20] explained that a key feature of connectivist learning is that much learning can be practiced through peer networks. In this regard, Garcia et al.'s study [9] found that staff and students' roles changed as a result of participation in a connectivist learning model through cooperative electronic blogs. Other studies found that educators realized that connecting instructional content to specific contexts of learners' lives increased motivation to learn.

Although connecting phase enhances and makes learning continue based on new technological inventions; and then learners make sense to new ideas, they still need to construct knowledge by themselves. So, connecting phase works as an initial and pre-step for the following phase of constructing knowledge; the phase which is actually needed to prove that there is something built by learners.

- Constructing: Knowledge is always the result of a constructive activity and therefore it cannot be transferred to a passive receiver. Effective learning begins with what learners bring to the learning situation. This includes cultural practices and beliefs as well as knowledge of academic content. Anyway, through this phase of Hendy's 4Cs model, the current level of understanding, which resulted in the previous phases, is taken as a starting point for constructing new things. So while the teacher should guide learners to relate the current events and previous knowledge, the learner should observe, analyze, and use previous knowledge to construct new knowledge. This inevitably results in effective constructing of learning by learners themselves.

Practically, Anwar in her study [1] found that a constructive learning strategy stimulated students' motivation, especially on the students' engagement in learning activities; that the more the students engaged, the more motivated they are. Arseven [2] explored that using a mathematical teaching program based on a constructive approach was very necessary to motivate students, eliminate their anxiety and allow them to develop positive attitudes towards mathematics.

Although constructive learning is based on sound theory and research, some criticized it as it works best only with learners from privileged backgrounds who already possess essential skills and school-oriented attitudes and behaviors. Others still say that the overuse of constructive strategies can lead to "group think" and discourage independent thinking and creative problem solving by highly talented individuals. Moreover, based on personal observations, it was noticed that some learners could not construct knowledge completely, either individually or cooperatively, through learning situations. So, many learners are in need to process information cognitively more and more through the coming fourth phase.

- Cognitivizing: Through the current phase, learners process information more deeply. According to the cognitivism, a meaningful learning is based on an assumption that the more meaningful information provided to individuals, the easier for them to process, learn, memorize, and apply [6]. Cognitivists explained that there is an internal cognitive structure which is named 'Schema' by which the coming new information can be compared with information already exists. This internal 
cognitive structure can be extended or changed to adapt the new information received [14]. Cognitivists also explained that there are three levels of memory; sensory memory, short-term memory, and long-term memory. To place information in long-term memory, which is an important benefit for this model, one must learn it in an effective way [14]. So, while the teacher should authentically assess learning to make elaboration, the learner should summarize, apply and make decisions regarding her/his learning. It is logically to say that as learners engage in the cognitive process, they actively reflect on and make decisions as they pursue learning goals.

Practically, a study by Moghaddam and Araghi [18] tried to demonstrate the connection between new findings of the brain function and cognitive approach to the language learning practices. The findings explained that students would be able to understand according to their own abilities and to interact effectively with teachers. Castro-Villarreal and Others [5] explored the importance of a modified cognitive model and suggested that cognitive motivational variables played important roles in promoting students' self-efficacy and final course grade.

What should be noted here is that some learners may do not have suitable internal schema that needed for some new information [14]. Also, there are what named 'contradictions' that may appear through encoding and storing new information when it does not consist with the personal schema. So, practicing the processes of this phase with those of other phases can overcome these challenges.

Based on above phases including roles of teacher and learner, several learning benefits can be attained by the 4Cs model [28]:

- Practicing the model phases and procedures effectively can lead directly to development of learner engagement, exploration of main ideas, learning connection, construction of knowledge, and deep learning as general outcomes for the four phases respectively as shown in Figure 1.

- Attaining those outcomes together can lead to the highest level of learning that would be appeared in meaningful learning. Meaningful learning occurs when new experiences are explored and related to what learner already knows. According to Ausubel, meaningful learning may be explained as a process of relating and connecting new material to old ones as a hierarchical fashion [18].

- By experiencing real contexts, using previous knowledge, and reflecting on selfconstructed knowledge through this model, information can be placed in long-term memory.

- It is expected that there is increasing in level of academic achievement, skills, attitudes, learning styles, multiple intelligences and engagement of learners.

\section{- Engagement of Learning-Disabled Students:}

Generally, student engagement reflects student's intellectual, behavioral, emotional, social, and cognitive experiences. It also refers to the quantity and quality of cognitive and emotional energy students exert to learn. In this regard, engagement can be attained when teachers use learning and teaching strategies and models that address those aspects of engagement in the suitable learning environment.

So educationally, engagement can be classified to many aspects such as behavioral, intellectual, social, emotional, and cognitive engagement. Behavioral engagement refers to involving students to attend, and practice activities inside learning situation. Intellectual engagement refers to involving students to be intellectually active through learning situation rather than only receiving ready theoretical information from teachers [11]. Moreover, educators refer that social engagement refers to share and participate instructional group activities and experiences. Emotional engagement refers to positive feelings and interests through learning. Cognitive engagement means that students think, keep ideas, solve problems, and reflect on accepted knowledge. Regarding learning disabled students, many factors can affect their engagement such as teacher enthusiasm, subject matter, methods of teaching, learning environment, and so on. The study of Brigham [4] indicated that teacher's enthusiasm helped learning-disabled students to be more interested and participate in learning process. A study conducted by Frideman et al. [8] indicated that Learning-disabled students were more academically engaged in the resource room than the regular class and also more engaged during teacher directed instruction than during seatback in both settings. The study also indicated that the degree of attending of learning disabled students was highly related to the context in which it occurs. The study of Omema [16] explored that a program based on a metacognitive strategy was effective in improving science process skills and science self-efficacy of students with learning disability in middle school. 


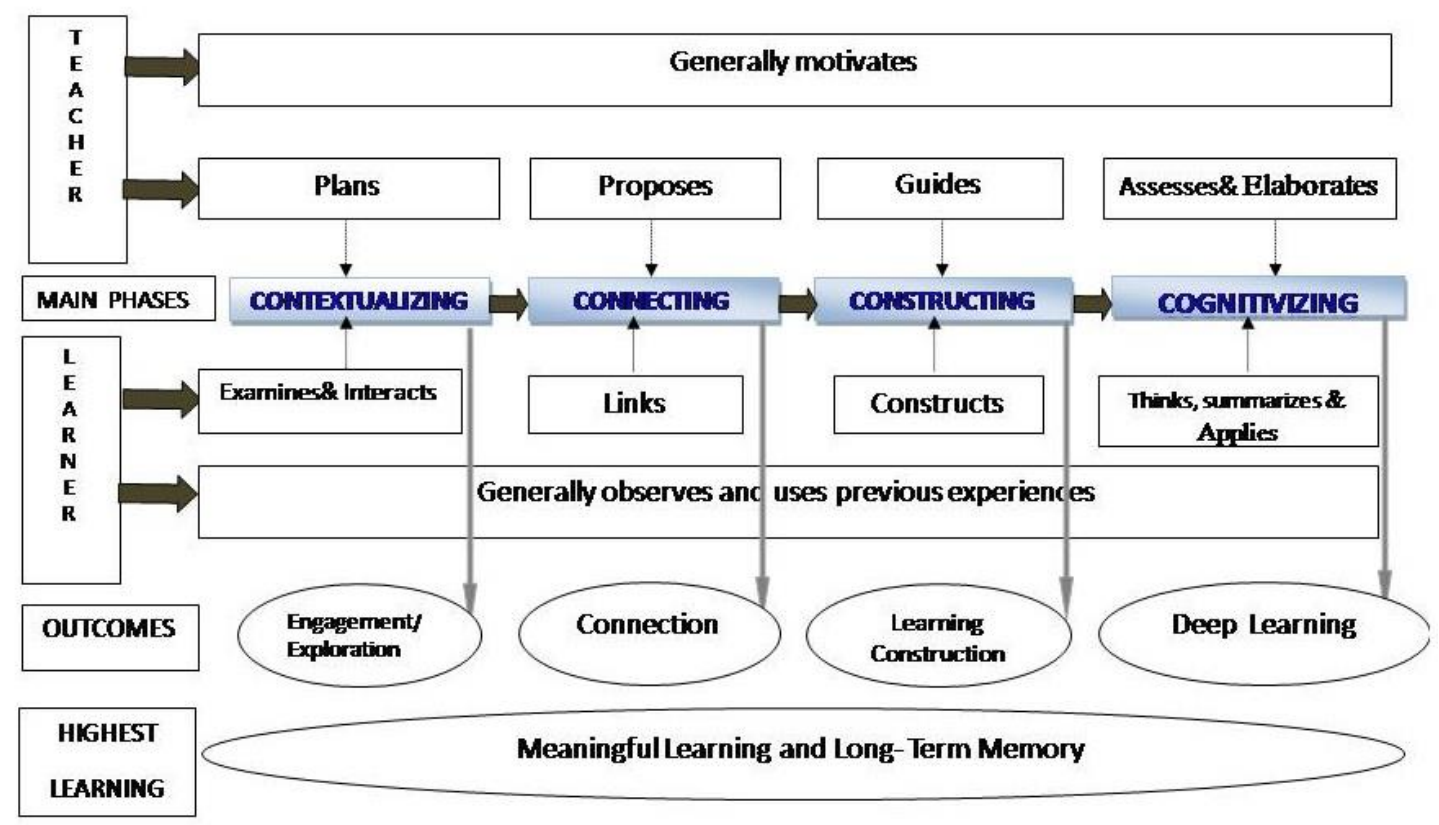

Hendy's 4Cs Model for Teaching and Leaming

Figure 1. Hendy's 4Cs Model for Teaching and Learning

\section{- Hendy's 4Cs Model and Engaging Learning-Disabled Students:}

Dewey (1938) asserted that students learn best when they are interested in the subject matter and that teachers should adjust instruction to support student interests. Edeh [7] explained that an interest-based method of teaching offered an effective cognitive strategy purposed to hold the attention of students with learning disabilities and keep them engaged in the activities. Edeh contended that the interest-based teaching method help maximizing the retention of the information learned. Moreover, cognitive strategy instruction has been effective in improving problem solving performance of students with disabilities. That cognitive instruction can help students with disabilities to process problems, facilitate learning and improve their overall performance.

In respect to Hendy's Model, it is obvious that the model has four main phases and then many learning procedures for teacher and students. So, students can recognize information and experiences because the relevance of the activities to their experiences. Teachers can incorporate and infuse diverse students interests in their teaching to make learning relevant to all of them. The materials in this model are prepared and created using students' actual interests.

Practically, a study conducted by Hendy [10] found that the model was effective in acquiring some multiple intelligences, scientific concepts, and life skills to middle school students in MidEgypt. another Hendy's study [11] found that Egyptian middle school teachers perceived the model as effective towards engaging middle school students intellectually, behaviorally, emotionally, and cognitively. Hendy's study [12] explored that Hendy's 4Cs Model was effective in respect to engaging college students socially and emotionally. Because the model is flexible and has multiple phases and procedures and has proven its importance in engaging students as mentioned above, it can help improve learning environment and help teachers for identification of children with learning disabilities in their classrooms and provide learning materials that engage them.

Moreover, there are many rationales behind Hendy's 4Cs Model that encourage using it with students with learning disabilities. The model is based on actual learning theories that have evidences towards attaining effective learning for all learners in different ages regardless of their varied problems and disabilities. It is an integrated physical mental journey that takes the learner from a contextual concrete situation to a full cognitive learning environment, and result in meaningful learning and long-term memory; this can be attained for all learners. The transition from contextual situation to knowledge application directly maybe not attained until learners connect, construct, process, and reflect on information. Putting 
learners in a real learning context at the beginning can lead them easily to connect, construct, and process information. Educators believe that learning is affected by the context in which an idea is taught. Also, the flexibility of using the model can allow using new varied assistive instructional technologies offered for now students with learning disabilities in all school levels.

In addition, teachers of students with learning disabilities can consider some conditions through learning to ensure the benefits of Hendy's 4Cs model for those students. Those conditions such as: offering continuous observation and interaction with students, and continuous motivation by the teacher. The teacher also should be effective in managing her/his classroom physical environment, time, and movement and communication among learners. To attain an effective cognitive trip through this model, the teacher should accept changes in her/his roles, and also changes in learning environment [11].

\section{Purpose and Objectives/questions}

The main purpose of this study was to determine opinions of Egyptian secondary school teachers on effectiveness of Hendy's 4Cs Model in engaging learning-disabled students. Taking the details of this purpose in account, two research questions were set as follow:

1) What are opinions of Egyptian secondary school teachers on effectiveness of Hendy's 4Cs Model in behavioral engagement of learningdisabled students?

2) What are opinions of Egyptian secondary school teachers on effectiveness of Hendy's 4Cs Model in cognitive engagement of learningdisabled students?

\section{Methodology}

The target population of this study was the secondary school teachers in Mid-Egypt through the academic year of 2018/2019. The research sample ( $n=120$ persons) was chosen randomly from among teachers who work in secondary schools of big number of learning-disabledstudents. Based on the study purpose, one research instrument; a three-point response scale was developed to include 20 items on behavioral engagement (10 items) and cognitive engagement (10 items). Content and face validity of the instrument were determined by a panel of experts specialized in teacher education and learning disabilities. The reliability coefficient was calculated for the scale using Cronbach's alpha. It was 0.81. After administering this scale as a part of a training program on using learning models based on learning theories to engage disabled students, data were entered and analyzed using SPSS to get the results.

\section{Results}

Research Question 1: What are opinions of Egyptian secondary school teachers on effectiveness of Hendy's 4Cs Model in behavioral engagement of learning-disabled students? To answer this question, frequencies and percentages of the sample responses were gotten and listed in Table 1. It is shown from Table 1 that items number $(1,2,4,5,7,8$, and 9) in part A (Behavioral Engagement) had the highest frequencies and percentages as "Agree". Those items are related to learning-disabled students to work effectively, use real instructional materials, write and pay more attention, behave individually and cooperatively, move actively, and take notes. On the other hand, items number $(3,6$, and 10) that are related to engaging disabled students to use available technology, behave according to their individual differences, and use verbal and nonverbal communication skills had the highest frequencies and percentage as "Uncertain". This indicates the effectively of the model regarding the behavioral engagement.

Research Question 2: What are opinions of Egyptian secondary school teachers on effectiveness of Hendy's 4Cs Model in cognitive engagement of learning-disabled students? To answer this question, frequencies and percentages of the sample responses were gotten and listed in Table 2 It is shown also from Table 2 that items number (2, 3, 5, 6, 7, and 8) in part B (Cognitive Engagement), had the highest frequencies and percentages as "Agree". These items are related to engaging disabled students to link knowledge to real the life, organize instructional materials, construct new knowledge, integrate ideas and experiences, and to be involved in problem solving processes. On the other hand items number $(1,4,9,10)$ that are related to engaging disabled students to explore main ideas, develop self-assessment abilities, reflect on knowledge, and apply what is learned in real life had the highest frequencies and percentages as "Uncertain". This indicates the effectively of the model regarding the cognitive engagement.

\section{Conclusion}

The current study explains that secondary school teachers who work in schools of big numbers of students with learning disabilities 
Table 1. Frequencies and percentages of respondents $(n=120)$

\begin{tabular}{|c|c|c|c|c|c|c|c|}
\hline \multirow[b]{2}{*}{ No } & \multirow[t]{2}{*}{ Items } & \multicolumn{2}{|c|}{ Agree } & \multicolumn{2}{|c|}{ Uncertain } & \multicolumn{2}{|c|}{ Disagree } \\
\hline & & \multirow[t]{2}{*}{ F } & \multirow[t]{2}{*}{$\%$} & \multirow[t]{2}{*}{$\mathrm{F}$} & \multirow[t]{2}{*}{$\%$} & \multirow[t]{2}{*}{$\mathrm{F}$} & \multirow[t]{2}{*}{$\%$} \\
\hline $\mathbf{A}$ & Behavioral Engagement: & & & & & & \\
\hline 1 & $\begin{array}{l}\text { The model starts by procedures that engage learning-disabled } \\
\text { students to work effectively. }\end{array}$ & 62 & 51.7 & 41 & 34.1 & 17 & 14.2 \\
\hline 2 & The model invites disabled students use real materials & 71 & 59.2 & 26 & 21.7 & 23 & 19.1 \\
\hline 3 & $\begin{array}{l}\text { The model encourages disabled students use available } \\
\text { technology in learning situation. }\end{array}$ & 30 & 25 & 64 & 53.3 & 26 & 21.7 \\
\hline 4 & The model encourages students write on work sheets, maps, etc.. & 59 & 49.2 & 32 & 26.6 & 29 & 24.2 \\
\hline 5 & $\begin{array}{l}\text { The model makes disabled students pay more attention to } \\
\text { instructional procedures. }\end{array}$ & 66 & 55.0 & 28 & 23.3 & 26 & 21.7 \\
\hline 6 & $\begin{array}{l}\text { The model helps students behave according to their individual } \\
\text { differences. }\end{array}$ & 34 & 28.3 & 65 & 54.2 & 21 & 17.5 \\
\hline 7 & $\begin{array}{l}\text { The model allows disabled students behave individually and } \\
\text { cooperatively }\end{array}$ & 71 & 59.2 & 19 & 15.8 & 30 & 25.0 \\
\hline 8 & $\begin{array}{l}\text { The model helps disabled students move actively through } \\
\text { practicing learning activities. }\end{array}$ & 66 & 55.0 & 32 & 26.6 & 22 & 18.4 \\
\hline 9 & $\begin{array}{l}\text { The model helps disabled students take notes during learning } \\
\text { situations. }\end{array}$ & 61 & 50.8 & 37 & 30.8 & 22 & 18.4 \\
\hline 10 & $\begin{array}{l}\text { The model encourages disabled students use verbal and non- } \\
\text { verbal communication skills }\end{array}$ & 33 & 27.5 & 57 & 47.5 & 30 & 25.0 \\
\hline
\end{tabular}

Table 2. Frequencies and percentages of respondents $(n=120)$

\begin{tabular}{|c|c|c|c|c|c|c|c|}
\hline \multirow{3}{*}{$\begin{array}{l}\text { No. } \\
1\end{array}$} & \multirow{3}{*}{$\begin{array}{l}\text { Cognitive Engagement: } \\
\text { The model helps disabled students explore main ideas. }\end{array}$} & \multicolumn{2}{|c|}{ Agree } & \multicolumn{2}{|c|}{ Uncertain } & \multicolumn{2}{|c|}{ Disagree } \\
\hline & & $\mathrm{F}$ & $\%$ & & $\%$ & & $\%$ \\
\hline & & 37 & 30.8 & 66 & 55.0 & 17 & 14.2 \\
\hline 2 & The model helps disabled students link knowledge to real life. & 63 & 52.5 & 33 & 27.5 & 24 & 20.0 \\
\hline 3 & $\begin{array}{l}\text { The model allows disabled students organize materials to } \\
\text { overcome memory disability }\end{array}$ & 69 & 57.5 & 30 & 25.0 & 21 & 17.5 \\
\hline 4 & $\begin{array}{l}\text { The model helps disabled students develop self-assessment } \\
\text { abilities. }\end{array}$ & 44 & 36.7 & 60 & 50.0 & 16 & 13.3 \\
\hline 5 & $\begin{array}{l}\text { The model encourages disabled students construct new } \\
\text { knowledge. }\end{array}$ & 71 & 59.2 & 30 & 25.0 & 19 & 15.8 \\
\hline 6 & $\begin{array}{l}\text { The model helps disabled students integrate ideas and } \\
\text { experiences. }\end{array}$ & 61 & 50.8 & 35 & 29.2 & 24 & 20.0 \\
\hline 7 & $\begin{array}{l}\text { The model encourages disabled students be involved in } \\
\text { problem solving processes. }\end{array}$ & 64 & 53.3 & 31 & 25.8 & 25 & 20.9 \\
\hline 8 & $\begin{array}{l}\text { The model helps disabled students outline and summaries } \\
\text { accepted information. }\end{array}$ & 60 & 50.0 & 38 & 31.6 & 22 & 18.4 \\
\hline 9 & The model encourages disabled students reflect on knowledge. & 33 & 27.5 & 78 & 65.0 & 9 & 7.50 \\
\hline 10 & $\begin{array}{l}\text { The model helps disabled students apply what is learned in real } \\
\text { life. }\end{array}$ & 45 & 37.5 & 56 & 46.7 & 19 & 15.8 \\
\hline
\end{tabular}

perceived using Hendy's 4Cs model as an effective model to engage learning-disabled students behaviorally and cognitively. So, the multiple phases and roles of both teacher and students through the model are beneficial to meet the multiple learning disabilities among high school students. The results here are consistent with results of many previous studies mentioned above regarding models related to the four learning theories and studies used Hendy's 4Cs Model.

\section{References}

[1] K. A. Anwar, Constructive Teaching Model in Learning Research Concept for English Language Teaching Students. International Education Studies. (2015), 8 (5), pp 62- 68.

[2] A. Arseven, Mathematical Modeling Approach in Mathematics Education. Universal Journal of Educational Research, (2015) 3, (12), pp. 973-980.

[3] F. Bell, Connectivism: A Network Theory for Teaching and Learning in Connected World. Educational Developments. The Magazine of the 
Staff and Educational Development Association, (2009), 10 (3).

[4] F. Brigham, Generating Excitement: Teacher Enthusiasm and students with Learning Disabilities. Paper Presented in the Annual Meeting of the Council for Learning Disabilities (Minneapolis, MN. ERIC Document (1991), ED340189.

[5] F. Castro-Villarreal, N. Guerra, D. Sass, \& P. Hseih, Models of Pre-Service Teachers' Academic Achievement: the Influence of Cognitive Motivational Variables. Journal of the Scholarship of Teaching and Learning, (2014) 14 (2) pp 71-95.

[6] Cruikshank, D.; Jenkins, D.\& Metcalf, K. (2006) The Act of Teaching. 4th Ed. New York: McGraw Hill.

[7] O. Edeh, Cross-Cultural Investigation of Interestbased and Social Interpersonal Problem Solving in Students with Mental Retention. Education and Training in Developmental Disabilities, (2006) 41 (2), 163-176.

[8] D. Friedman, \& others. Academic Engagement of Elementary School Children with Learning Disabilities. Paper presented at the Annual Convention of the American Psychological' Association, ERIC Document. (1987) ED294340.

[9] E.Garcia, I.Elbeltagi, M. Brown, and K. Dungay, The Implications of Constructivist Learning Blog Model and the Changing Role of Teaching and Learning. British Journal of Educational Technology, (2015), 46, (4), pp 877-894.

[10] M. H. Hendy, The Effect of Using Hendy,s 4Cs Model on teaching and Learning Science in Middle School in Mid-Egypt, Journal of Teaching and Education, (2016) 2, 5, (2016), pp. 233-242.

[11] M. H. Hendy, Egyptian Middle School Teachers' Perceptions of the Effect of Hendy's 4Cs Model on Students' Learning Engagement, International Journal of Educational Science and Research, (2017 a), 7(1) pp. 55-64.

[12] M. H. Hendy, The Effect of Using Hendy's 4Cs Model Accompanied by Teacher Social Support to Help College Students Be Socially and Emotionally Engaged, International Conference for Academic Disciplines. University of London, (2017 b, 7-10 November).

[13] P. Hutchinson, Children Designing \& Engineering: Contextual Learning Units in Primary Design Technology. Journal of Industrial Teacher Education, (2002), 39 (3) pp. 1-21.

[14] Kathleen, M. College Reading\& Study Skills. 9th ed. New York: Pearson Longman, (2004).

[15] K. Kurniati, S. Yaya, J.Sabandar, and T. Herman, Mathematical Critical Thinking Ability through Contextual Teaching and Learning Approach. Indonesian Mathematical Society.
Journal on Mathematics Education, (2015), 6 (1) pp. 53-62.

[16] G. Omema, The Effect of Metacognitive Strategy Training on Science Process Skills and Self Efficacy among First Year Prep Students with Learning Disabilities. International Journal of PsychoEducational Science, (2016). 5 (3), pp121-129.

[17] J. Merrifield, Equipped for the Future Research Report: Building the Framework, (1993-1997). Washington, D. C.: National Institute for Literacy. (2000) Available on: http://www.nifl.gov/lincs/ collections/eff/merrifield_eff.pdf.

[18] A. Moghaddam, and S. Arghi, Brain-based Aspects of Cognitive Learning Approaches in Second language. English Language Teaching, (2013), 6 (5) pp. 55-61. Published by Canadian Center for Science Education.

[19] Pierangleo, R. and Giuliani, G. What Every teacher Should Know about Students with Special Needs: Promoting Success in the Classroom, Research Press, Champaign, Illinois, (2001).

[20] G. Siemens, Connectivism: A Learning Theory for the Digital Age. International. Journal of Instructional Technology and Distance Learning, (2005), 2 (1) pp 3-10. 